\title{
Validity of needle core biopsy in the histological characterisation of mammary lesions
}

\author{
Calogero Cipolla*, Salvatore Fricano, Salvatore Vieni, Carmela Amato, \\ Liborio Napoli, Giuseppa Graceffa, Stefania Latteri, Mario Adelfio Latteri
}

\author{
Division of General and Oncological Surgery, Department of Oncology, University of Palermo, \\ Palermo, Italy
}

Received 17 July 2004; accepted 6 January 2005

KEYWORDS

Core biopsy;

Breast cancer;

Diagnosis

\begin{abstract}
Summary Over the last few years, there has been an enormous increase in the use of needle core biopsy (CB) for the histopathological characterisation of suspect lesions of the breast. The aim of this study was to verify the diagnostic reliability of $C B$ by comparing the histological results obtained with the use of this technique with those obtained from the whole of the surgically resected specimen. We studied 198 out of 426 patients with clinically and/or radiologically suspect breast lesions. We found correspondence between the histological examination of the whole of the excised specimen and that of the CB in $94.9 \%$ of the cases of infiltrating carcinoma and in $71.4 \%$ of those involving ductal carcinomas in situ. The predictive value of $C B$ was $98.9 \%$, sensitivity was $96.1 \%$ and specificity $93.3 \%$. These results confirmed that $\mathrm{CB}$ is an extremely reliable diagnostic tool in the definition of breast lesions.

(C) 2005 Elsevier Ltd. All rights reserved.
\end{abstract}

\section{Introduction}

Over the last few years, there has been a considerable increase in the use of needle core biopsy (CB) for the histopathological characterisation of suspect breast lesions and it has now become a first-choice diagnostic procedure replacing traditional excisional biopsy. ${ }^{1,2}$ It follows, therefore, that as the use of $\mathrm{CB}$ becomes more

\footnotetext{
*Corresponding author. Tel.: +3991 6554520; fax: +39916554429 .

E-mail address: calogero.cipolla@tin.it (C. Cipolla).
}

and more frequent, there will be a concomitant reduction in the number of diagnostic surgical biopsies and intraoperative histological examinations. $^{1}$

Several published reports have demonstrated that in a high percentage of cases the histological results of $C B$ concur with those obtained from the examination of the whole of the excised specimen. ${ }^{3-9}$ Furthermore, CB provides an extremely high level of diagnostic reliability, not only with regard to cases of infiltrating carcinoma, but also to those involving atypical hyperplasia, lobular carcinomas in situ, ${ }^{10-16}$ ductal carcinomas in situ 
$(\mathrm{DCIS})^{4,5,8,11,14,16,17}$ and to a large number of benign breast diseases. ${ }^{18,19}$

Although CB has not completely replaced traditional excisional biopsy, it is considered to be a valid diagnostic procedure, since it is not only efficient but also well tolerated and not particularly invasive, making it possible for the surgeon to provide the patient with a great deal of information regarding her disease and to plan a more specific therapeutic approach.

The aim of this study is to verify the reliability of $\mathrm{CB}$ for the diagnosis of breast lesions by comparing the histological results obtained using this procedure with those resulting from the examination of the whole of the excised specimen, in a consecutive series of suspect breast lesions, in order to evaluate the possible routine use of $C B$ instead of surgical biopsy in the diagnostic work-up of such lesions.

\section{Materials and methods}

Four hundred and twenty-six consecutive patients with clinically and/or radiologically suspect breast lesions underwent CB in our Institute from September 1999 to February 2004. In 302 cases (70.9\%), there was only a radiological suspicion of the lesions since they were not clinically palpable. These lesions, with or without microcalcifications, presented a Breast Imaging Reporting and Data System (BI-RADS) risk of 3-5. In 124 cases (29.1\%), the lesions were not only identified by X-ray but were also clinically palpable. In all cases the lesions were evaluated both by a breast X-ray specialist and by a surgeon.

Surgical excision was performed in 198 cases (46.5\%) and the histological CB result was compared with that obtained from the whole of the excised specimen. Ninety-two of these lesions (46.5\%) were clinically palpable, while 106 (53.6\%) were not (Table 1 ).
Six months and 1 year after the $C B$, the remaining 228 patients (53.5\%) underwent clinical and X-ray examinations of their lesions, and the benign status of the lesions obtained from the histological results of the $C B$ was found to be compatible with the clinical and mammographic diagnosis of probable benignity (BI-RADS 3 ).

$C B$ was performed with 14-gauge needles. Two to five stereotactically guided samples (with an average of three) were taken from each of the non-palpable lesions, while in the 92 clinically palpable lesions the $C B$ was performed manually with ultrasound guidance.

From a histological point of view, the lesions were classified as infiltrating carcinomas (IC), DCIS, hyperplasia with atypical cells $(\mathrm{AH})$ and benign lesions (BL). The results of the histological examinations of the whole of the excised specimens were then compared with those obtained from the CB.

In all the cases, the operations were performed by expert breast surgeons and decisions regarding the type and extent of the procedure were based both on the histological evaluation of the $C B$ and on the clinical and/or mammographic characteristics of the lesions. Where the $\mathrm{CB}$ examination produced a clinically and/or mammographically confirmed diagnosis of IC, quadrantectomy or full mastectomy was performed, associated with complete axillary dissection or with biopsy of the sentinel lymph node. In all the other cases, only the lesion was surgically removed.

Where the lesions were clinically non-palpable, they were localised before surgery by the stereotactically guided insertion of a metal thread. Correct removal of the lesion was confirmed by an X-ray of the excised specimen.

\section{Results}

In our Institute, from September 1999 to February 2004, CBs were performed on 426 clinically and/or

Table 1 Description of the 426 lesions investigated using core biopsy.

\begin{tabular}{lccr}
\hline & Surgical removal & Follow-up & Total \\
\hline Clinically and/or radiologically suspect lesions & 92 & 32 & 124 \\
Radiologically suspect lesions (clinically non-palpable): & & & \\
BI-RADS 3 & 18 & 196 & 214 \\
BI-RADS 4 & 45 & - & 45 \\
BI-RADS 5 & 43 & - & 43 \\
Total & 198 & 228 & 426 \\
\hline
\end{tabular}


radiologically suspect breast lesions. In 228 cases $(53.5 \%)$ histological examination by CB produced a benign result, confirmed by the clinical and mammographic features of the lesion. In these patients, clinical and X-ray examinations were repeated 6 months and 1 year after CB. During these follow-up examinations, in no cases were any changes observed that might require a re-evaluation by a second $\mathrm{CB}$ or the surgical removal of the nodule for histological examination of the operated specimen.

In 198 cases $(46.5 \%)$ it was possible to compare the $\mathrm{CB}$ result with that obtained from the excisional biopsy. In 106 cases (53.5\%) the mammary lesions were non-palpable, while 92 cases (46.5\%) involved clinically palpable lesions.

The histological examination of the 198 lesions performed on the whole of the excised specimens diagnosed 176 (88.9\%) ICs, 7 (3.5\%) DCIS, 10 (5.1\%) AHs and 5 (2.4\%) BLs (Table 2).

CB examination of the 92 palpable mammary lesions resulted in $90(97.8 \%) \mathrm{ICS}$, one $(1.1 \%)$ DCIS and one $(1.1 \%) \mathrm{AH}$. In all these cases $(100 \%)$, these results were confirmed by the histological examination of the whole lesion after surgical removal.

Histological examination of the whole of the excised specimens from the 106 non-palpable lesions resulted in $86(81.1 \%)$ cases of IC, six (5.6\%) of DCIS, nine $(8.5 \%)$ of $\mathrm{AH}$ and five $(4.7 \%)$ of BL. Of the 86 cases of IC, 77 (89.5\%) were confirmed by $C B$, while in five cases $(5.8 \%)$ $\mathrm{CB}$ produced a diagnosis of $\mathrm{AH}$, in three cases $(3.5 \%)$ of DCIS and in one case $(1.2 \%)$ of $B L$. Histological examination of the CB in the six DCIS cases resulted in four cases $(66.7 \%)$ of DCIS, one case $(16.6 \%)$ of $\mathrm{AH}$ and one case $(16.6 \%)$ of IC. In all nine cases of $\mathrm{AH}(100 \%)$ there was agreement between the histological examination of the $C B$ and of the whole of the surgical specimen, and one $(20 \%)$ of the five BL cases was confirmed by the CB examination. This particular case involved an adenomyoepithelioma, which is a fairly uncommon breast tumour.
In conclusion, therefore, correspondence between the histological examination performed on the $C B$ sample and that obtained from the excised specimen was found in all $(100 \%)$ of the palpable lesions and in $94(88.6 \%)$ of the non-palpable lesions. Of the 176 cases of IC identified by the histological examination of the excised specimen, CB confirmed the diagnosis in 167 (94.9\%), while five $(71.4 \%)$ of the seven DCIS were also confirmed by $C B$. This indicated a positive predictive value (PPV) for the CB technique of $98.9 \%$, sensitivity of $96.1 \%$ and specificity of $93.3 \%$. If the 228 patients with lesions undergoing $\mathrm{X}$-ray follow-up after a CB histological result of benignity are included as true negatives, the specificity of the method is even higher and reaches $99.1 \%$ (Table 3 ).

\section{Discussion}

Over the last few years, there has been such an increase in the use of needle $C B$ for the histological characterisation of suspect breast lesions that, where possible, it is now always advised as the first-choice procedure for the histological definition of breast lesions in place of traditional excisional biopsy. ${ }^{1,2}$

Although without doubt one of the great advantages of the method is that it can be used for radiologically suspect preclinical lesions, its use can also be extended to the study of clinically palpable lesions in order to confirm a clinical and X-ray diagnosis of fairly probable or even certain carcinoma. In this way, at the moment of surgery, the therapeutic approach has already been defined, making it possible to avoid intraoperative biopsy. Furthermore, in cases in which preoperative chemotherapy is indicated, CB provides not only the histological typing of the tumour, but also a definition of the prognostic factors without the use of surgical biopsy.

$\mathrm{CB}$ makes it possible to avoid the surgical removal of those lesions for which a diagnosis of

Table 2 Histological results of 169 excised lesions.

\begin{tabular}{|c|c|c|c|c|c|c|}
\hline & \multicolumn{2}{|c|}{ Clinically non-palpable lesions } & \multicolumn{2}{|c|}{ Clinically palpable lesions } & \multicolumn{2}{|c|}{ Total } \\
\hline & No. & $\%$ & No. & $\%$ & No. & $\%$ \\
\hline Infiltrating carcinoma & 86 & 81.1 & 90 & 97.8 & 176 & 88.9 \\
\hline Ductal carcinoma in situ & 6 & 5.6 & 1 & 1.1 & 7 & 3.5 \\
\hline Atypical hyperplasia & 9 & 8.5 & 1 & 1.1 & 10 & 5.1 \\
\hline Benign lesions & 5 & 4.7 & & & 5 & 2.5 \\
\hline Total & 106 & 100 & 92 & 100 & 198 & 100 \\
\hline
\end{tabular}


Table 3 Histological results of core biopsy compared with those of excisional biopsy.

\begin{tabular}{|c|c|c|c|c|c|}
\hline \multirow[t]{2}{*}{ Core biopsy } & \multicolumn{5}{|c|}{ Surgical biopsy } \\
\hline & $\begin{array}{l}\text { Infiltrating } \\
\text { carcinoma }\end{array}$ & $\begin{array}{l}\text { Ductal carcinoma } \\
\text { in situ }\end{array}$ & $\begin{array}{l}\text { Atypical } \\
\text { hyperplasia }\end{array}$ & $\begin{array}{l}\text { Benign } \\
\text { lesion }\end{array}$ & Total \\
\hline Infiltrating carcinoma & 167 & 1 & & 1 & 169 \\
\hline Ductal carcinoma in situ & 3 & 5 & & & 8 \\
\hline Atypical hyperplasia & 5 & 1 & 10 & & 16 \\
\hline Benign lesions & 1 & & & 4 & 5 \\
\hline Total & 176 & 7 & 10 & 5 & 198 \\
\hline
\end{tabular}

Positive predictive value $98.9 \%$; sensibility $96.1 \%$; specificity $93.3 \%$.

benignity has been confirmed by the clinical and radiological features. In our experience, in 228 patients $(53.5 \%)$ in whom the histological result of the $C B$ diagnosed benignity and in whom the lesion did not demonstrate any features that might be considered clinically or radiologically suspect, surgical removal was not performed, resulting in a reduction in cost and a high level of patient compliance. In all the cases concerned, ultrasound and radiographic examinations performed 6 months and 1 year after $\mathrm{CB}$ showed no modifications of the lesions. It goes without saying, therefore, that $C B$ made it possible to avoid the surgical removal of such lesions.

Although our results demonstrate that most of the CBs performed by us involved BL that did not require surgery, the majority of the lesions that were surgically removed after $C B$ proved to be malignant. Of the 198 patients undergoing surgery after $C B, 176$, in fact, had ICs and seven had DCIS, making a total of 183 malignant neoplasias, or $92.4 \%$ of all the patients operated on. Of the nonpalpable lesions removed, 86 were ICs and six were DCIS, totalling 92 malignancies out of 106 surgically removed lesions $(86.7 \%)$. Of the palpable lesions removed, 90 were ICs and one was a DCIS, out of a total of 92 lesions removed (98.9\%).

In only 15 cases $(7.6 \%)$ did the lesions that were removed prove to be benign, but 10 of these $(66.7 \%)$ involved lesions demonstrating atypical histological features, while one was an adenomyoepithelioma diagnosed by $C B$ as an IC. In four cases $(2 \%)$, the lesions removed after $C B$ proved to be benign, but all were non-palpable lesions removed using the stereotactically guided advanced breast biopsy instrument (ABBI) method and diagnosed histologically as fibroadenomas of the breast.

The low rate of surgical removal for $B L$ and, on the other hand, the high incidence of malignant neoplasias, are in our experience most likely due to the careful, accurate selection methods used for the indications for $C B$. This is the result not only of several years of study and work involving preclinical breast lesions, but also of extremely fruitful multidisciplinary cooperation in our Institute between radiologists, surgeons and pathologists. This fact concurs with recently published reports on the same subject by several other authors ${ }^{1-5}$ and, furthermore, emphasises the fact that, in the last few years, experience with the use of $C B$ has led to an increase in the diagnosis of ICs using this procedure, compared with the results published a few years ago, ${ }^{3,6,8,10}$ when the rates of diagnosis of breast carcinomas using $C B$ ranged from $8 \%$ to $42 \%$.

Another fact that emerged from our own study is the high correspondence between the histological examination of the $C B$ and the traditional excisional biopsy, which was $93.9 \%$. In fact, in the 92 palpable lesions, there was $100 \%$ correspondence between $C B$ results and those of the traditional surgical biopsy, while in the 106 non-palpable lesions, in only seven out of 92 cases $(6.6 \%)$ did the $\mathrm{CB}$ examination give a false-negative result, although six of these cases involved an $\mathrm{AH}$. In only one case $(0.94 \%)$ did the histological examination of $\mathrm{CB}$ give a false-positive result; the histological examination of the surgical specimen diagnosed this case as an adenomyoepithelioma, which is in fact a fairly breast tumour.

In our opinion, $C B$ histologic underestimation concerns mostly non-palpable lesions and does not present any particular problems. Histological examination of the $C B$ produced a completely benign result in only one case out of the 86 non-palpable $\mathrm{ICs}$; in five cases it resulted in an $\mathrm{AH}$ and in three cases a DCIS, all lesions requiring surgical removal in order to perform a complete histological evaluation. In any case, however, it should be borne in mind that before any decision is made, the CB histologic result should be compared with those of the clinical and/or radiological examinations, and surgical removal should be performed if the 
latter produces a highly suspect result, even though the $\mathrm{CB}$ produced a benign result.

The positive predictive value of $C B$ in the definition of the histological nature of the lesion (98.9\%) and the sensitivity of the method (96.1\%) both proved to be extremely high. One hundred and eighty-three of the 198 surgically removed lesions were in fact malignant. CB specificity was also high at $99.1 \%$, since if all 228 patients with a benign histological result from CB in whom surgery was not performed, but who were subjected to X-ray follow-up are considered true negatives, the number of BL removed was extremely low. Furthermore, in ten patients $(66.7 \%)$ in whom BL were removed, the lesions proved to be cell atypia, which should in any case be removed.

\section{Conclusions}

In conclusion, our results concur with those of previously published reports, i.e. that $C B$ is an extremely efficient tool for the histological definition of breast lesions. Since the positive predictive value of the technique is very high, a positive histological result for malignant neoplasia with the use of $C B$ should be taken fairly seriously with regard to therapeutic programming and information given to the patient, as confirmed by several other authors, ${ }^{15}$ and may make it possible to avoid intraoperative biopsy. Only if there is discordance between the histological results of the $C B$ and the $X$-ray result should surgical biopsy be considered imperative. In any case in which the lesion is radiologically or clinically suspect, however, even when the CB leads to a benign histological result, it is extremely important to make a careful evaluation of the correspondence between the mammographic result, the clinical features of the lesion and the histological findings, and to proceed if necessary to surgical biopsy.

\section{References}

1. Crowe JP, Rim A, Patrick RJ, Rybicki LA, Grundfest SF, Kim $\mathrm{JA}$, et al. A prospective review of the decline of excisional breast biopsy. Am J Surg 2002;184:353-5.

2. Liberman L. Impact of percutaneous image-guided core biopsy on the clinical management of breast disease. In: Rose P, editor. Breast pathology: diagnosis by needle core biopsy. Philadelphia: Lippincott Williams \& Wilkins; 1999. p. 291-300.
3. Litherland J. The role of needle core biopsy in the diagnosis of breast lesions. Breast 2001;10:383-7.

4. Mikhail RA, Nathan RC, Weiss M, Tummala RM, Mullangi UR, Lawrence $\mathrm{L}$, et al. Stereotactic core needle biopsy of mammographic breast lesions as a viable alternative to surgical biopsy. Ann Surg Oncol 1994;1:363-7.

5. Liberman L, Dershaw DD, Rosen PP, Giess CS, Cohen MA, Abransim AF, et al. Stereotaxic core biopsy of breast carcinoma: accuracy at predicting invasion. Radiology 1995;194:379-81.

6. Jackman RJ, Burbank F, Parker SH, Evans WP, Lechner MC, Richardwon TR, et al. Stereotactic breast biopsy of nonpalpable lesions: determinants of ductal carcinoma in situ underestimation rates. Radiology 2001;218:497-502.

7. Gisvold JJ, Goellner JR, Grant CS, Donohue JH, Sykes MW, Karsell PR, et al. Breast biopsy: a comparative study of stereotaxically guided core and excisional technique. Am J Roentgenol 1994;162:815-20.

8. Adler DD, Light RJ, Granstrom P, Hunter TB, Hunt KR. Follow-up of benign results of stereotactic core breast biopsy. Acad Radiol 2000;7:248-53.

9. Acheson MB, Patton RG, Howisey RL, Lane RF, Morgan A. Histologic correlation of image-guided core biopsy with excisional biopsy of nonpalpable breast lesions. Arch Surg 1997;132:815-21.

10. Verkooijen HM, Peeters PHM, Buskens E, Koot VCM, BorelRinkes IHM, Mali W, et al. Diagnostic accuracy of large-core needle biopsy for nonpalpable breast disease: a metaanalysis. Br J Cancer 2000;82:1017-21.

11. Simon JR, Kalbhen CL, Cooper RA, Flisak ME. Accuracy and complication rates of US-guided vacuum-assisted core breast biopsy: initial results. Radiology 2000;215:694-7.

12. Moore MA, Hargett CW, Hanks JB, Fejardo LL, Harvey JA, Frierson HF, et al. Association of breast cancer with the finding of atypical ductal hyperplasia at core breast biopsy. Ann Surg 1997;6:726-33.

13. Margolin FR, Leung JWT, Jacobs RP, Denny SR. Percutaneous imaging-guided core breast biopsy: 5 years' experience in a community hospital. Am J Roentgenol 2001;177:559-64.

14. Liberman L, Cohen MA, Dershaw DD, Abramson AF, Hann LE, Rosen PP. Atypical ductal hyperplasia diagnosed at stereotaxic core biopsy of breast lesions: an indication for surgical biopsy. Am J Roentgenol 1995;164:1111-3.

15. Liberman LL, Dershaw DD, Glassman JR, Abramson AF, Morris EA, LaTrenta LR, et al. Analysis of cancers not diagnosed at stereotactic core breast biopsy. Radiology 1997;203:151-7.

16. Jackman RJ, Nowels KW, Shepard MJ, Finkelstein SI, Marzoni FA. Stereotaxic large-core needle biopsy of 450 nonpalpable breast lesions with surgical correlation in lesions with cancer or atypical hyperplasia. Radiology 1994;193:91-5.

17. Ely KA, Carter BA, Jensen RA, Simpson JF, Page DL. Core biopsy of the breast with atypical ductal hyperplasia. Am J Surg Pathol 2001;25:1017-21.

18. Bonnett M, Wallis T, Rossmann M, Pernick NL, Carolin KA, Segel $M$, et al. Histologic and radiographic analysis of ductal carcinoma in situ diagnosed using stereotactic incisional core breast biopsy. Mod Pathol 2002;15:95-101.

19. Burak WE, Owens KE, Tighe MB, Kemp L, Dinges SA, Hitchcock CL, et al. Vacuum-assisted stereotactic breast biopsy: histologic underestimation of malignant lesions. Arch Surg 2000;135:700-3.

Available online at www.sciencedirect.com

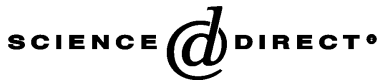

